\title{
Optoelectronic properties of New Synthesized phtalocyanine
}

\section{Sarra TOUAITI, Amira HAJRI, Mourad Shédy KAHWECH, Bassem JAMOUSSI}

Laboratoire de Chimie Organique et Analytique. Institut Superieur de l'Education et de la Formation Continue. Bardo, Tunisie

Email address:

Touatisarah5@yahoo.fr(S. TOUAITI)

\section{To cite this article:}

Sarra TOUAITI, Amira HAJRI, Mourad Shédy KAHWECH, Bassem JAMOUSSI. Optoelectronic Properties of New Synthesized Phtalocyanine. International Journal of Materials Science and Applications. Vol. 2, No. 6, 2013, pp. 179-184.

doi: $10.11648 /$ j.ijmsa.20130206.13

\begin{abstract}
One novel Zn-phthalocyanine bearing different substituent was synthesized. The resulting compounds were characterized by NMR and FTIR. The corresponding polymer was synthesized via cyclic voltametry. The optical properties of these $\pi$-conjugated systems were investigated by UV-Visible absorption and photoluminescence (PL) spectroscopy. The electrochemical behavior was reported. The optical and electrochemical gaps were estimated. Those complexes, having low gap energy, have been identified as holding much promise for the developpement of photovoltaic device.
\end{abstract}

Keywords: Phthalocyanine, Polymer Poly (Zn-Pc), Electrochemical Conductivity, UV Conductivity

\section{Introduction}

Metallo - Phthalocyanine (PCs) is a metal organic compound with four pyrole units linked to form symmetrical $18 \pi$ - electron aromatic macrocycle, allowing the incorporation of more than 70 metals or non-metal ions into their inner core.

Due to its high thermal and chemical stability, these conjugated compounds have attracted much research interest in the fabrication of electronic molecular devices such as opto-electronic devices [1], gas sensors [2,3], static induction transistors [4], and photoreceptor devices in laser beam printers and photocopiers [5]. Phthalocyanine thin films exist in many polymorphic forms depending on their growth conditions.

A major disadvantage of PCs is their low solubility in organic solvents even in dimethylsulfoxyde (DMSO) and it has been overcome by introducing electron-donating substituents[6], electron-withdrawing substituents or polar ionizable substituents. A suitable fonctionalization of the PCs has a strong influence on the $\pi$-electron conjugation of the macromolecule since it makes salvation easier, decreasing thus the gap energy (the difference between HOMO and LUMO orbital).

Recent advances in synthetic methods and chromatographic separation techniques have made possible a wide range of new $\mathrm{Pc}$ derivatives with different substituent. Consequently, a variety of functionalized Pc derivatives have now become available, and their spectroscopic and electrochemical properties have been studied extensively in order to develop these for technological applications [7].

Firstly, we report the synthesis and characterisation of new Zn (II) phthalocyanine (ZnPC) tetrasubstituted by (2phormyl-4-methoxy) groups and the corresponding polymer (poly (Zn-Pc)). UV - Visible spectroscopy, Fourier Transform Infrared Spectrophotometry (FT-IR) and fluorescence spectrophotometry. are used to confirm the formation of phthalocyanine tetrasubstituted . Secondly, the electrochemical properties of synthesized phtalocyanine were reported. Finally, single-layer devices fabricated using vacuum deposition based on an indium-tin-oxide/Znphthalocyanine/aluminum, and characterized by photoluminescence and electric measurement.

\section{Experimental}

\subsection{Materials and Measurement}

N,N'-dimethylformamide (DMF), Dimeth ylsulfoxyde (DMSO), diethylether, chloroform were freshly used, alcohols and initiator products were used as received from Aldrich. 4-nitrophtalonitrile was synthesized from phtalic anhydride using procedure with four steps, Potassium carbonate $\left(\mathrm{K}_{2} \mathrm{CO}_{3}\right)$ was dried before use.

$1 \mathrm{H}-\mathrm{NMR}$ spectral data were obtained on a AV 300 spectrometer. FTIR spectra were acquired on a Perkin- 
Elmer BX FT-IR system spectrometer by dispersing sample in $\mathrm{KBr}$ pellets. UV-Vis absorption spectra were recorded on a Cary 2300 spectrophotometer. Photoluminescence (PL) spectra were obtained on a Spectra-Physics stabilite 2017 spectrometer model 3900S.

\subsection{Synthesis}

The synthesis of the macrocycle zinc (II) phthalocyanines $\mathrm{ZnPc}$ begins with the nitration in position 4 of phthalimide followed by reaction of the amine hydroxide, to form the 4-nitrophthalamide 2. The dehydration of 2 by the thionyl chloride in $\mathrm{N}, \mathrm{N}-$ dimethylformamide leads to 4-nitrophthalonitrile 3 (scheme 1).

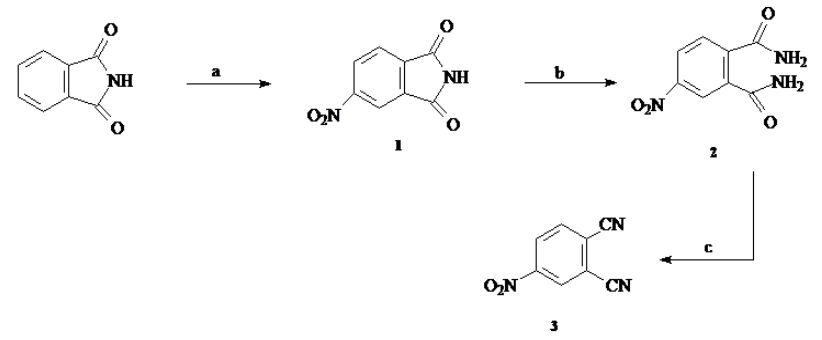

Scheme 1. Reaction conditions: (a) $\mathrm{HNO}_{3}, \mathrm{H}_{2} \mathrm{SO}_{4}, 0^{\circ} \mathrm{C}, 5 \mathrm{~h}$; (b) $\mathrm{NH}_{2} \mathrm{OH}$ $25 \%$; (c) DMF, $\mathrm{SOCl}_{2}$, $0-2^{\circ} \mathrm{C}, 5 \mathrm{~h}$

Dinitriles 4 were prepared by a nucleophilic substitution reaction of 4-nitrophthalonitrile with the corresponding alcohol in the presence of $\mathrm{K}_{2} \mathrm{CO}_{3}$ (scheme 2).

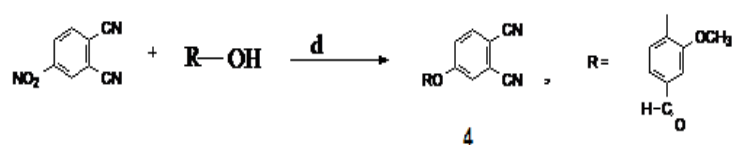

Scheme 2. Reaction conditions: (d) $\mathrm{K}_{2} \mathrm{CO}_{3}$, DMSO, room temperature, 48 $\mathrm{h}$

The cyclo-tetramerisation of dinitriles compound with zinc (II) acetate in the presence of urea and ammonium molybdate was performed in nitrobenzene (scheme 3 ).

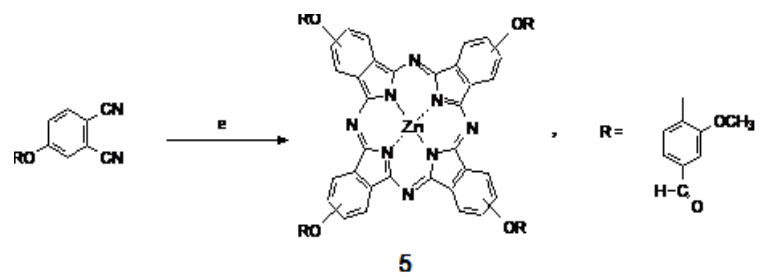

Scheme 3. Reaction conditions: (e) $\mathrm{ZnOAc}_{2}$, nitrobenzene, urea and ammonium molybdate

\subsubsection{Synthesis of 4-Nitrophthalimide 1}

4-nitrophtalimide 1 was prepared by nitration of phtalimide using nitric acid and sulfuric acid in presence of an ice bath as described before by Hajri.A [8].

$R M N{ }^{1} H\left(D M S O-d_{6}\right): \delta: 8.003(d, J=5.7 \mathrm{~Hz}, 1 \mathrm{H}) ; 8.342$ $(s, 1 H) ; 8.540(d, J=6.9 \mathrm{~Hz}, 1 \mathrm{H}) ; 11.761(s, 1 H) . R M N{ }^{13} \mathrm{C}$ (DMSO- $\left.d_{6}\right) \delta: 118.16 ; 124.92 ; 129.87 ; 134.42 ; 137.66$; $151.71 ; 167.61 ; 167.91$.

\subsubsection{Synthesis of 4-Nitrophthalamide 2}

4-Nitrophtalimide was stirred in $32 \%$ ammonia solution (70mL) for 24 hours to obtain 4-nitrophtalamide 2 . The resulting deep yellow product was filtered and washed with cold water until the excess of ammonia could not be detected. The title compound was dried at $110{ }^{\circ} \mathrm{C}$, a $95 \%$ yield. $R M N{ }^{1} H(D M S O-d 6): \delta: 7.636(s, 2 H) ; 7.704(d$, $J=8.1,1 H) ; 8.020(s, 1 H) ; 8.079(s, 1 H) ; 8.297(d d, J=2.4$ $\mathrm{Hz}, J=8.7 \mathrm{~Hz}, 1 \mathrm{H}) ; 8.338(\mathrm{~d}, J=2.1 \mathrm{~Hz}, 1 \mathrm{H}) . R M N{ }^{13} \mathrm{C}$ (DMSO-d6) $\delta: 122.35 ; 124.38 ; 129.11 ; 137.19 ; 142 ; 65$; $147.02 ; 167.67 ; 168.67$.

\subsubsection{Synthesis of 4-Nitrophthalonitrile 3}

The 4-nitrophthalamide 2 was converted to 4nitrophthalonitrile via dehydration of the amide by using thionyl chloride and DMF as solvent.

$R M N^{1} H(D M S O-d 6): \delta: 8.439(d, J=8.7,1 H) ; 8.685(d d, J$ $=2.1 \mathrm{~Hz}, J=8.4 \mathrm{~Hz}, 1 \mathrm{H}) ; 9.033(d, J=2.1,1 \mathrm{H}) . R M N^{13} \mathrm{C}$ (DMSO-d6) $\delta: 114.55 ; 114.86 ; 116.59 ; 120.22 ; 128.52$; $128.81 ; 135.27 ; 149.69$

FTIR: 3091 (C-H aromatic), 2242 (CN), 1534 (asymmetric $N=O$ band), 1349 (symmetric $N=O$ band), 853 $(C-N)$.

\subsubsection{Synthesis of Dinitriles 4}

(2-phormyl-4-methoxy)phenoxyphtalonitrile 4. To a mixture of 4-nitrophtalonitrile $3\left(0.5 \mathrm{~g}, 2.88 .10^{-3} \mathrm{~mol}\right)$ and Vaniline $\left(0.438 \mathrm{~g}, 2.88 .10^{-3} \mathrm{~mol}\right)$, in DMSO was added anhydrous $\mathrm{K}_{2} \mathrm{CO}_{3}\left(4.03 .10^{-3} \mathrm{~mol}, 0.571 \mathrm{~g}\right)$. The mixture was stirred for a further $48 \mathrm{~h}$. Then, the reaction mass was poured into water $(25 \mathrm{~mL})$ and the precipate formed was filtered off, washed with water, and crystallized from EtOH-water to give the product as a yellow crystalline powder. Yield: $60 \%{ }^{1} \mathrm{H}-\mathrm{NMR}(300 \mathrm{MHz}, \mathrm{CDCl}$, ppm): $7.2(\mathrm{~d}, \mathrm{~J}=8.7 \mathrm{~Hz}, 1 \mathrm{H}), 7.6(\mathrm{t}, \mathrm{J}=7.7 \mathrm{~Hz}, \mathrm{~J}=2.5 \mathrm{~Hz}, 1 \mathrm{H}), 7.76-8$ $(\mathrm{m}, 5 \mathrm{H}), 8.5(\mathrm{t}, \mathrm{J}=8.5 \mathrm{~Hz}, \mathrm{~J}=2.7 \mathrm{~Hz}, 1 \mathrm{H}), 8.8(\mathrm{~d}, \mathrm{~J}=8.75 \mathrm{~Hz}, 1 \mathrm{H})$. $R M N{ }^{13} C$ (DMSO-d6) $\delta: 108 ; 118 ; 119 ; 122.51 ; 128 ; 136$; $137 ; 148 ; 150 ; 163$.

\subsubsection{Synthesis of Phthalocyanines Derivatives 5}

Phtalocyanine PC5. A mixture of (2-phormyl-4methoxy)phenoxyphtalonitrile $4 \quad$ (0.2 mol), $\mathrm{ZnAC}_{2}(0.010 \mathrm{~mol})$, molybdate $\operatorname{sel}(0.02 \mathrm{~g})$ and urea( $\left.20 \mathrm{~g}\right)$ was refluxed in nitrobenzene for 7 hours at $170^{\circ} \mathrm{C}$. Then methanol and water were added to induce precipitation. The solid was filtered and washed sequentially with water and methanol. The solid was dried under vaccum to give $45 \%$ of pure product as a green powder. The structure of the phtalocyanine was confirmed by UV-vis absorption, NMR and FTIR.

\subsection{Fabrication and Characterization of Device}

The organic photovoltaic cell monolayers are generally described as Schottky type Single-layer devices were elaborated as sandwich structure between an aluminum (Al) cathode and an indium tin oxide (ITO) anode as seen in figure 1 . 


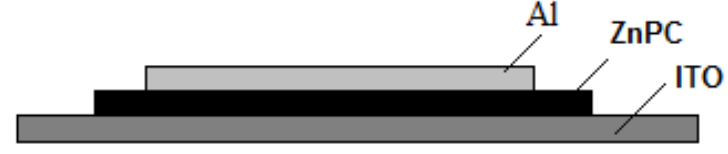

Figure 1. The structure of the device fabricated

The clean of the ITO glass is a step of great importance enabling the adhesion of the organic materials deposited thereafter. The slides are cleaned by successive rinsing, with desionised water, warm acetone and warm ethanol for 10 min each time in an ultrasonic bath.

The phtalocyanines compounds solutions $\left(3.10^{-2} \mathrm{M}\right.$ in DMF) were evaporated onto ITO glass to obtain a film about $40 \mathrm{~nm}$ thick. The glass slide was $15 \mathrm{~mm} \times 10 \mathrm{~mm} \times 1.1 \mathrm{~mm}$ with a $120-160 \mathrm{~nm}$ thick layer of ITO. A thin aluminum layer $(150 \mathrm{~nm})$ was deposited by thermal evaporation at $3.10^{-6}$ Torr. Devices were fabricated and characterized in air at room temperature.

\section{Results and Discussion}

In general, zinc phthalocyanine $(\mathrm{ZnPC})$ is known to show poor solubility in organic solvents, and strong tendency to aggregate due to its planar conjugated structure, for these reason we introduce substituents in their structures.

The phtalonitriles derivatives were synthesized following the method employed before in our labotory [9]. Complexs 6 was prepared by the template reaction of the phtalonitrile derivative (precursor) with zinc acetate and urea in nitrobenzene.

The PC5 complex was found to be more soluble (completely), then non subtistuted zn-phtalocyanine [10], in dimethylformaamide and dimethylsulfoxide. The new compound obtained in this study was been characterized as far as possible by spectroscopic techniques (IR and ${ }^{1}$ HNMR).

The formation of phtalocyanine compound was confirmed by the disappearance of the characteristic nitrile $(\mathrm{C} \equiv \mathrm{N})$ stretch at $2226 \mathrm{~cm}^{-1}$ present in compound 4 (Figure2).

The IR spectrum of PC5 are very similar to those seen in literature. Aromatic C-H peaks were observed around 3032 $\mathrm{cm}^{-1}$ and aromatic C-O-C stretching was observed at 1225 $\mathrm{cm}^{-1}$. The stretching frequency of methoxy group was observed at $2760 \mathrm{~cm}^{-1}$. And the adehyde group seen was observed at $1690 \mathrm{~cm}^{-1}$.

In the ${ }^{1} \mathrm{H}-\mathrm{NMR}$ spectrum of PC5 taken in DMSO-d6, the methoxy protons appeared as multiplets at $3.8 \mathrm{ppm}$, the aromatic protons as multiplets from 7.74 to $6.93 \mathrm{ppm}$ and the formyl protons a singulet at $11.1 \mathrm{ppm}$.

The Q band of the PC5 complex in DMF was typical of nonaggregated species, as it can be observed on Fig 3, at concentrations lower than $5 \times 10-5 \mathrm{M}$. It's shown that PC5 exhibit the typical optical features of phtalocyanines: a broad absorption band at around $348 \mathrm{~nm}$, assigned to the Soret band of the phthalocyanine moiety and a strong one at $681 \mathrm{~nm}$ assigned to Q-absorption band.

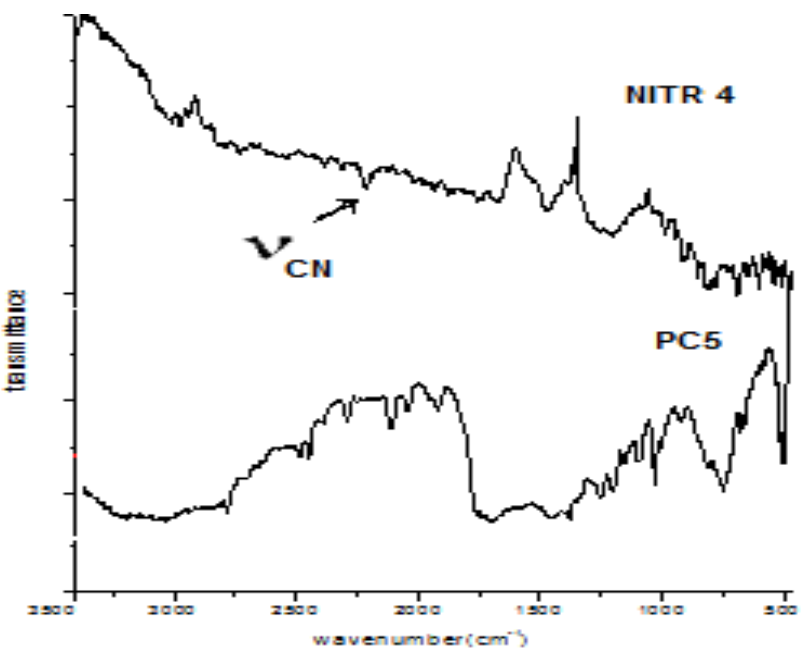

Figure 2. IR-spectroscopy spectra of PC5

\subsection{Optical Properties}

The UV-Visible absorption and photoluminescence spectra of PC5 were recorded at room temperature, in diluted DMF solutions and in thin solid film while those of Poly(PC5) in electrodeposited film.

\subsubsection{UV-Vis Absorption Spectroscopy}

Absorption spectrum seems to be the most important characteristic of phtalocyanines complexes and related compounds. The ground state electronic spectra are especially useful to identify the structure of these macrocycles.

ITO conductive glass electrodes were used to obtain the UV-visible absorption spectra of the electropolymerized films.

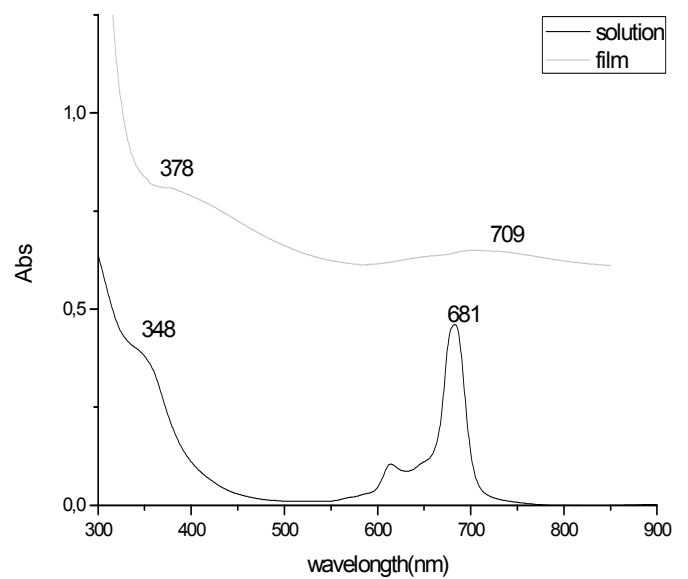

Figure 3. UV-vis absorption spectra of PC5 [thin film and dilute solution in $\left.D M F\left(5.10-{ }^{-5} \mathrm{M}\right)\right]$ 


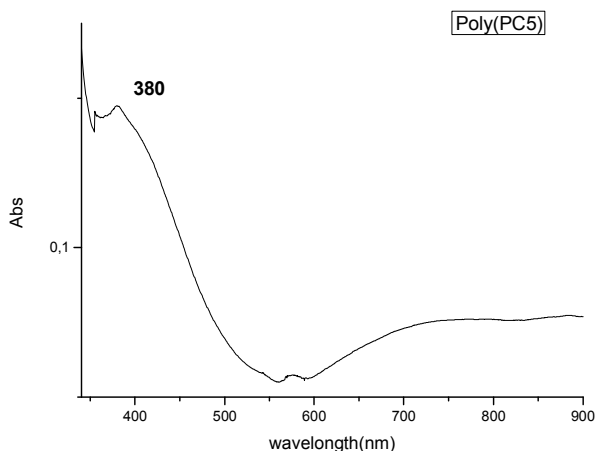

Figure 4. UV-vis absorption spectra of Poly (PC5)

In dilute solution, the spectrum shows two absorption maxima at 348 , and $681 \mathrm{~nm}$ which are the characteristic band of phtalocyanine (Figure 3). Nevertheless, the spectrum was slightly redshifted $(11 \mathrm{~nm})$ in comparison with that of nonsubstuted phtalocyanine [10,11]. This behavior can be in fact attributed to the electronic effect of methoxy and formyl groups.

The optical band gaps were estimated from the absorption onset of the polymer films and according to the formula $\mathrm{E}=\mathrm{hc} / \lambda$. The calculated value was 1.75 for PC5 and lower then 1.37 for Poly(PC5) as shown in table 1.

Table 1. $\lambda \max (\mathrm{nm})$, and $\lambda$ onset(nm) optical band gap (ev) of PC5(film), PC5(solution) and Poly(PC5)

\begin{tabular}{lllll}
\hline Compounds & $\boldsymbol{\lambda}$ max/nm & & $\begin{array}{l}\lambda \\
\text { onset/nm }\end{array}$ & $\begin{array}{l}\text { Optical band } \\
\text { gap } \mathbf{E}_{\text {gap op }}(\mathbf{e v})\end{array}$ \\
& $\mathbf{B}$ band & $\mathbf{Q}$ band & & \\
\hline PC5(solution) & 348 & 681 & 706 & 1.75 \\
PC5(Film) & 378 & 709 & 834 & 1.48 \\
Poly(PC5) & 380 & $\begin{array}{l}\text { Higher } \\
\text { then } 822\end{array}$ & $\begin{array}{l}\text { Higher } \\
\text { then } 900\end{array}$ & Lower then 1.37 \\
\hline
\end{tabular}

Going from solution to film the PC5 absorption spectrum preserves the same allure while shifting toward the lowest energies. This bathochromic effect was assigned to the pstacking of the phtalocyanine moieties and aggregate formation in the solid state. An optical band gap of $1.48 \mathrm{eV}$ was estimated from the absorption onset of the film sample. Comparing monomer and polymer film (Figure 4) we note that the second one was red shifted which can be explained by the conjugation growth.

\subsubsection{Photoluminescence Measurements}

The luminescence properties of the materials were studied by analyzing the photoluminescence spectra of the material in the visible region with wavelength excitation of $488 \mathrm{~nm}$. The sample for PL spectra was loaded on a solution and film sample. Figure 5 and Figure 6 shows the photoluminescence spectra of PC5 (solution and film) and Poly(PC5)( electrodeposited film) respectively.
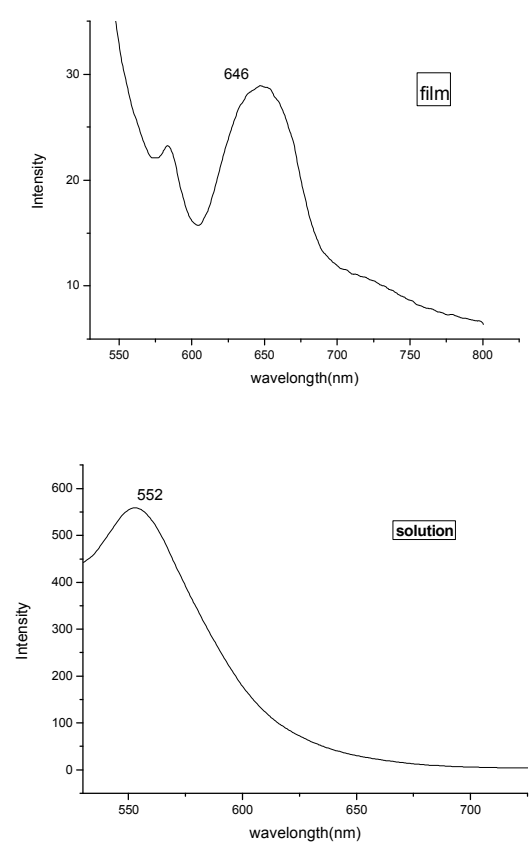

Figure 5. PL spectra of PC5 in thin films and dilute solutions in DMF $\left(5.10-{ }^{5} \mathrm{M}\right)$

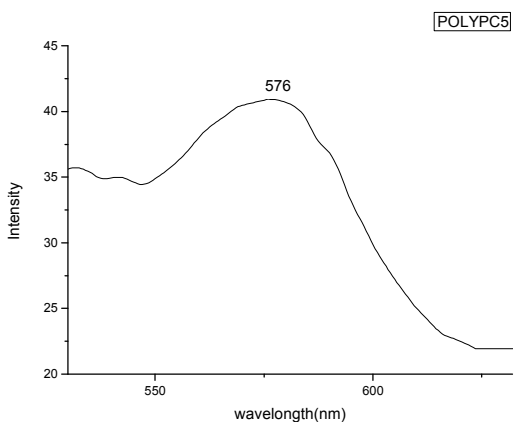

Figure 6. $P L$ spectra of polyZnPC

The $\mathrm{p}-\mathrm{p}$ stacking of conjugated moieties also influenced the film emission, and broad, redshifted PL spectra were obtained as a result to excimer formation in comparison with the solution spectra [12]. An important red emission (646nm) was observed for PC5 (film), and a green emission was obtained $(563 \mathrm{~nm})$ for PC5 (solution). In the case of the Poly(PC5), a yellow emission was detected (576nm) which is certainly explained by the growth of the conjugation .

\section{2.Electrochemistry}

\subsubsection{Electrochemical Measurement}

This technique provides information on the position of the energy levels (the highest occupied molecular orbital (HOMO) and the lowest unoccupied molecular orbital (LUMO)). The electrochemical experiments were performed, by cyclic voltametry, at room temperature in a conventional three electrode cell. The glass ITO was utilized as working electrode, platinium wire as auxiliaire 
electrode and ECS as reference electrode and scanned in $\mathrm{LiClO}_{4} /$ dimethylformaamid.

All processes are ring based since the central $\mathrm{Zn}$ metal is electroinactive [13,14]. Complex PC5 exhibits one irreversible oxidation pics at $0.437 \mathrm{~V}$ and a reversible reduction pic at $-1.55 \mathrm{~V}$. The voltamogrammes obtained are shown in figure 7.

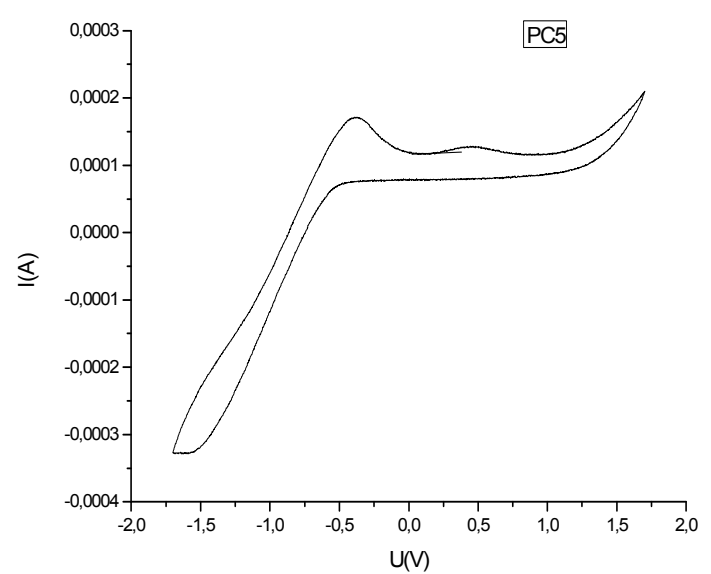

Figure 7.Cyclic voltammograms of $\mathrm{PC} 5$ in $0.1 \mathrm{M} \mathrm{LiclO}_{4} / \mathrm{DMF}$ (scan rate: $100 \mathrm{mVs}^{-1}$ Working electrode $=I T O$, Auxiliaire electrode $=$ platinium wire and reference electrode $=E C S$ )

The HOMO energy level ( $\left.\mathrm{E}_{\mathrm{HOMO}}\right)$, LUMO energy level $\left(\mathrm{E}_{\mathrm{LUMO}}\right)$, and the electrochemical gap $\left(\mathrm{E}_{\mathrm{g} \text {-el }}\right)$ were calculated according to an empirical method [15]. The calculated EHOMO, ELUMO and $\mathrm{E}_{\text {gap el }}$ values are summarized in Table 2.

Table 2. Specific $E_{\text {Номо }}(V), E_{L U M O}(V)$ and electrochemical band gap (ev) of PC5

\begin{tabular}{cccc}
\hline & $\boldsymbol{E}_{\text {Hомо }}$ & $\boldsymbol{E}_{\text {LUMо }}$ & $\begin{array}{c}\text { Electrochemical gap } \\
\boldsymbol{E}_{\text {gap el }}(\mathrm{ev})\end{array}$ \\
\hline PC5 & -4.33 & -2.35 & 1.98 \\
\hline
\end{tabular}

\subsubsection{Electropolymerization of PC5 on ITO Electrodes}

The deposition of the phtalocyanine complex onto indium tin oxide electrodes by electrochemical polymerizations of the phtalocyanine complex was accomplished by cycling the potential applied to the working electrode from $2 \mathrm{~V}$ to $-2 \mathrm{~V}$.

After 100 scan (Figure 8) we note an increase in currents of the voltammogram envelop which indicates that a deposit was formed on the electrode. Thus, different phtalocyanine film thickness can be obtained by controlling the number of the electropolymerizing scans.

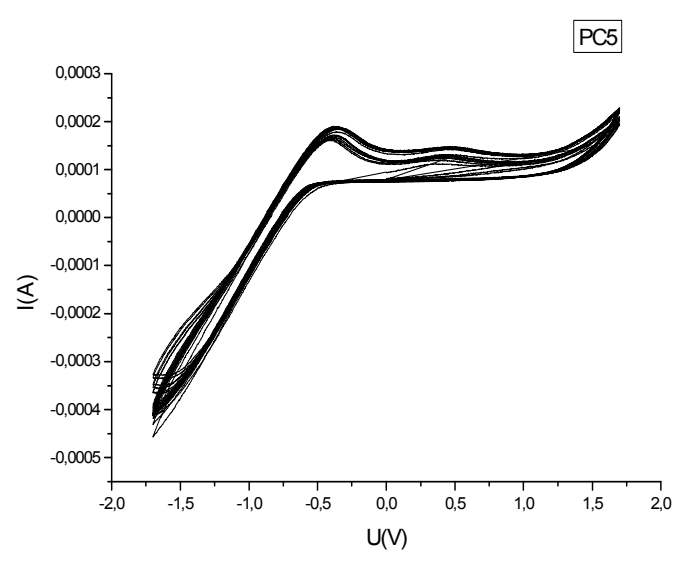

Figure 8. Cyclic voltammograms of $\mathrm{PC} 5$ in $0.1 \mathrm{M} \mathrm{LiclO}_{4} / \mathrm{DMF}$ (scan rate: $100 \mathrm{mVs}^{-1}$ Working electrode $=I T O$, Auxiliaire electrode $=$ platinium wire and reference electrode $=E C S$ )

\subsection{Current - Voltage Measurements}

The measurement of current-density (J) - voltage (V) characteristics is an important technique for characterizing diode. Tow single-layer devices with an ITO/PC/Al configuration were fabricated to investigate the currentvoltage (I-V) characteristics of the phtalocyanine based materials.

As shown in Figure. 8, the two I-V curves are very close and indicate typical diode behavior with relatively low turn-on voltages of 1.33 and $1.39 \mathrm{~V}$ for Poly(PC5) and PC5 respectively. Nevertheless, no electroluminescence could be recorded for these simple devices. The reason is probably unbalanced charge injection which increases the probability of radiation less exciton quenching at the electrode/phtalocyanine material interface [16]. Therefore, we consider that the devices turn-on voltages indicate the threshold of a hole-governed unipolar injection. In fact, work is in progress to built electroluminescent photovoltaic devices.

\section{Conclusion}

A Zn-phtalocyanine semi-conducting materials (PC5) was synthesized and characterized by UV and IR spectroscopy. Electrochemically, we have synthesized a new polymeric compound with yellow emission. The optical study revealed that in thin film, the emission was red-shifted when compared with solution and that the optical gap changed from 1.75 to $1.48 \mathrm{eV}$ The I-V characteristics of devices with an (ITO/PC5/Al) and (ITO/Poly(PC5)/Al) configurations demonstrate typical diode behavior with relatively low turn-on voltages. All these features make these compounds promising active materials for phtalocyanine-based OLEDs. 


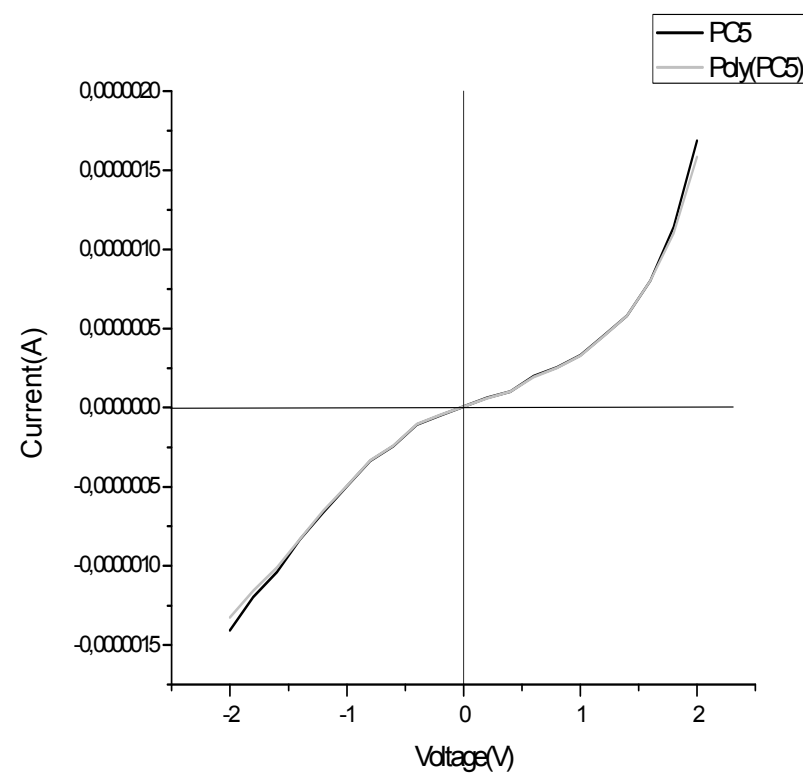

Figure 9. Current-voltage curves for [ITO/PC5//Al] and [ITO/Poly(PC5)/Al] devices

\section{References}

[1] G. Waltera, B. Rudineb and C. Wamser, Journal of Porphyrins and Phthalocyanines 14 (2010) 759-792.

[2] S.Radhakrishnan and S.D.Deshpande,Sonsors 2 (2002) 185194.

[3] Inta Muzikante, Vicente Parra, Rorijs Dobulans, Sonsors 7 (2007) 2984-2996.
[4] Michael Kraus,Stefan Richler,Andreas Opitz, Wolfgang Brütting,JOURNAL OF APPLIED PHYSICS 107 (2010) 094503.

[5] Bahittin KAHVEC, Selami S,AS,MAZ1, Musa OZIL1, Turk J Chem 30 (2006) $681-689$.

[6] G.L.Apkhomov, L.G.Pakhomov, Russian chemical Bulletin 44 (1995) 8

[7] PETER Gregory, Journal of Porphyrins and Phthalocyanines 4 (2000) 4 .

[8] Amira Hajri, Sarra Touaiti, and Bassem Jamoussi, Advance in optoelectronics (2013) 7.

[9] J. S. Michael, [thesis of doctorate], Faculty of the Virginia Polytechnic Institute and State, Blacksburg, Va, USA, 2006.

[10] B. I. Kharisov, U. Ortiz Méndez, J. L. Almaraz Garza, New journal of chemistry 29 (2005) 686-692.

[11] Keiichi Sakamoto and Eiko Ohno-Okumura, Materials, 2 (2009) 1127-1179.

[12] K.Hiz, N.Jaballah, M.Chamli, J.Mater Science, 47 (2012) 8067-8075.

[13] Yasin Arslanoglua, Atıf Kocab, Esin Hamuryudan, Polyhedron, 26 (2007)891-896.

[14] Kun Wang, Qiang Fu, JiCheng Ma, WeiLi Li, WenJu Li, Yang Hou, Science china chemistry, 55 (2012) 18721880.

[15] K.Hiz, N.Jaballah, M.Chamli, Jounal of Applied Polymer Science, 119 (2011)1443-1449.

[16] Ndayikengurukiye, H,Jacobs S., Tachelet W., Van Der Looy, Pollaris A., Geise HJ., Ciaeys M., Kauffmann JM, Janietz S., Tetrahedron, 53 (1997) 13811. 